\title{
WORKSHOP PEMANFAATAN TEKNOLOGI INTERNET OF THINGS (IOT) MENGGUNAKAN MIKROKONTROLER ESP32 UNTUK GURU-GURU SMK
}

\author{
Muhammad Yusro dan Aodah Diamah \\ Universitas Negeri Jakarta \\ Email: $\underline{\text { myusro@unj.ac.id }}$
}

\begin{abstract}
The rapid advancement of information technology and telecommunications has caused Internet of Things (IoT) technology to be increasingly developed and utilized in various activities and tasks at the home, office, school, industry, and others. 24-hour connectivity and various automation features make IoT an effective way to remotely monitor and manage jobs. In the context of learning in Vocational High Schools (SMK), ideally, the use of IoT technology applications is taught by teachers in the field of industrial electronics expertise. The uneven understanding and technical skills of teachers about the application of IoT technology is one of the factors that have not updated the ability of vocational students with IoT technology information. From these problems, the solution offered is to provide technical knowledge and skills to teachers about the use of IoT using a microcontroller so that they can teach it to students. The workshop/training was conducted online which was attended by 20 (twenty) teachers from several vocational schools in the Jakarta, Bekasi, Cibinong, and Bogor areas. In this workshop, theoretical and practical learning about the use of IoT technology is given. The material taught is the development of IoT, the use of the ESP32 IoT development board, and some practical examples using the ESP32 board. In this workshop, IoT learning e-modules (theory and practice) were also distributed which can be used by teachers for independent learning and as teaching materials in SMK. From the workshop, an overview of the understanding and technical skills of teachers regarding IoT technology was obtained which still needs to be improved. The participants were very enthusiastic about participating in the IoT workshop because they got new and useful information and knowledge to improve their competence in the field of industrial electronics technology. The usefulness of this workshop was felt by the participants who gave a positive impression of the material taught by the instructor/lecturer.
\end{abstract}

Keywords: ESP32; IoT; microcontroller; SMK

Abstrak
Pesatnya kemajuan teknologi informasi dan telekomunikasi, menyebabkan teknologi Internet of Things
(IoT) makin berkembang dan dimanfaatkan dalam berbagai kegiatan dan tugas di rumah, kantor, sekolah,
industri, dan lainnya. Konektivitas 24 jam serta berbagai fitur otomasi menjadikan IoT sebagai cara efektif
untuk memantau dan mengelola berbagai pekerjaan dari jarak jauh. Dalam konteks pembelajaran di
Sekolah Menengah Kejuruan (SMK), maka idealnya pemanfaatan aplikasi teknologi IoT diajarkan oleh
para guru bidang keahlian elektronika industri. Belum meratanya pemahaman dan keterampilan teknis
guru tentang aplikasi teknologi IoT, menjadi salah satu faktor belum ter-update nya kemampuan siswa
SMK dengan informasi teknologi IoT. Dari permasalahan tersebut maka solusi yang ditawarkan adalah
dengan memberikan pengetahuan dan keterampilan teknik kepada guru tentang pemanfaatan IoT
menggunakan mikrokontroler sehingga dapat mengajarkannya kepada siswa. Workshop/pelatihan
dilaksanakan secara daring yang diikuti peserta guru dari beberapa SMK di wilayah Jakarta, Bekasi,
Cibinong dan Bogor sebanyak 20 (dua puluh) orang. Dalam workshop ini diberikan pembelajaran teori
dan praktikum tentang pemanfaatan teknologi IoT. Materi yang diajarkan adalah perkembangan IoT,
pemanfaatan ESP32 IoT development board, dan beberapa contoh praktikum menggunakan ESP32 board.


Dalam workshop ini juga dibagikan e-modul pembelajaran IoT (teori dan praktik) yang dapat digunakan para guru untuk pembelajaran mandiri dan sebagai bahan ajar di SMK. Dari workshop tersebut didapatkan gambaran terkait pemahaman dan keterampilan teknis para guru tentang teknologi IoT yang masih perlu ditingkatkan. Para peserta sangat antusias mengikuti workshop IoT karena mendapatkan informasi dan pengetahuan yang baru dan berguna untuk meningkatkan kompetensinya di bidang teknologi elektronika industri. Kebermanfaatan workshop ini dirasakan sekali oleh para peserta yang memberikan kesan positif dari materi yang diajarkan oleh instruktur/narasumber.

Kata Kunci: ESP32, IoT; mikrokontroler; SMK

\section{PENDAHULUAN}

Perkembangan Internet of Things (IoT) di dunia saat ini telah banyak memberikan manfaat bagi kehidupan manusia (Firdaus \& Mulyana, 2018). Selain itu, IoT juga merupakan sebuah peluang bisnis yang sangat menjanjikan (Wantiknas, 2020). Indonesia sebagai negara dengan tingkat pertumbuhan pengguna internet yang tinggi tentu juga akan terdampak oleh tren teknologi ini. Indonesia sebagai sebuah negara yang sedang maju dan berkembang, tidak hanya memiliki potensi yang besar pada sektor e-commerce dan platform pembayaran. Dengan pesat nya perkembangan teknologi, IoT pun sudah mulai berkembang dan dapat dimanfaatkan untuk membantu berbagai kegiatan dan tugas manusia di rumah, kantor, jalan, sekolah dan lainnya. IoT tidak terbatas pada konteks industri saja, namun bisa juga digunakan untuk kebutuhan sehari-hari, seperti home voice control, bel pintu, lampu pintar, monitor polusi ruangan, dan sebagainya (Telkomsel, 2020) (Sakti et al., 2021).

IoT adalah suatu sistem di mana terhubung dan terintegrasinya perangkat satu dengan yang lainnya. Internet merupakan jaringan penghubung antar perangkat sehingga dapat terintegrasi (Chieochan et al., 2017). Hasil dari integrasi perangkat tersebut menghasilkan kode atau data yang dapat digunakan untuk berbagai macam keperluan manusia. IoT menggunakan pemrograman untuk menghasilkan interaksi antar mesin tanpa campur tangan manusia (JSC, 2017). Interaksi tersebut memanfaatkan konektivitas internet yang tersambung secara terusmenerus. Komunikasi antar mesin atau benda yang menggunakan teknologi IoT dapat berupa pertukaran data atau pengendalian jarak jauh. Teknologi ini menjadi pendukung utama pembangunan kota pintar atau smart city (Sushanth \& Sujatha, 2018).

Asosiasi IoT Indonesia (ASIOTI) melihat ada tiga sektor yang tumbuh pesat dalam menggunakan perangkat yang terhubung dengan internet (IoT) saat pandemi, yakni kesehatan, pertanian dan energi (ASIOTI, 2020). Pertama, digital healthcare ini dipaksa untuk tumbuh dengan demikian pesat, seperti contoh untuk mulai ke retail market thermal detection, kemudian remote monitoring tumbuh dengan pesat (Bansal \& Gandhi, 2018). Kedua, pada sektor pertanian kebutuhan akan remote monitoring juga sangat tinggi (Mishra et al., 2018) (Shri Pradha et al., 2019). Ketiga, penggunaan perangkat IoT ada pada sektor energi, dalam hal ini bisa 
dari energi air, energi listrik dan energi gas, untuk melakukan monitoring tugas/pekerjaan yang dilakukan oleh sensor-sensor (Nasir et al., 2018) (Nguyen et al., 2018) (Saber \& Al-Salihi, 2017).

Di masa depan, teknologi akan mengambil peran yang lebih besar dalam operasi dan manajemen perusahaan (Telkomsel, 2020). Data akan menjadi penentu utama dalam pengambilan keputusan. Visibilitas usaha serta transparansi data yang diberikan IoT akan membuka dinding-dinding pembatas antara departemen/perusahaan. Keterbukaan ini akan mendorong akuntabilitas pegawai serta memacu kinerja yang efektif waktu dan produktif. Nilai teknologi IoT di perusahaan akan lebih dari sekedar alat pendukung, namun sebagai penggerak utama usaha. IoT adalah solusi komunikasi antar mesin yang dapat memberi visibilitas usaha secara realtime. Konektivitas 24 jam disertakan berbagai fitur otomasi menjadikan IoT sebagai cara efektif untuk memantau dan mengelola usaha/pekerjaan dari jarak jauh, sehingga sumber daya yang ada bisa dialihkan untuk mengurus kebutuhan lainnya yang lebih penting.

Di Indonesia terkait dengan kemajuan teknologi informasi, Kemendikbud melalui Direktorat Jenderal Pendidikan Vokasi (Ditjen Diksi) menyebutkan ada 5 (lima) aspek yang perlu dikuasai sumber daya manusia (SDM) untuk menghadapi revolusi $4.0 \mathrm{ini}$, yaitu, internet of things, artificial intelligence, human machine interface, robotic and sensor technology, serta 3D printing technology (Kemendikbud, 2020). Di sinilah peran IoT menjadi hal yang menarik untuk dipelajari sebagai bentuk antisipasi mengenai jenis pekerjaan yang juga akan berubah. Dalam konteks pembelajaran di Sekolah Menengah Kejuruan (SMK), maka sudah seharusnya siswa mendapatkan wawasan pengetahuan sekaligus keterampilan tentang IoT yang tidak terbatas pada Program Keahlian TIK saja, namun untuk semua program keahlian. Logikanya untuk dapat mengajarkan siswa terkait materi IoT, maka para guru pun harus dibekali dengan pengetahuan dan keterampilan pemanfaatan IoT di berbagai bidang, khususnya yang terkait dengan peralatan rumah tangga dan industri.

\section{TINJAUAN LITERATUR}

Perkembangan dan pemanfaatan teknologi mikrokontroler telah merambah ke berbagai sektor kehidupan masyarakat. Produk teknologi mikrokontroler juga dapat diterapkan di berbagai bidang, baik di industri maupun masyarakat. Mikrokontroler banyak digunakan mulai dari peralatan pendidikan, perangkat elektronik rumah tangga, alat bermain anak, perangkat pendukung otomotif, peralatan industri, peralatan telekomunikasi, peralatan medis dan kedokteran, sampai dengan pengendali robot serta militer (Gunther Gridling, 2007). Seiring dengan kemajuan teknologi mikrokontroler itu, maka berkembang pula pemanfaatan dan aplikasi mikrokontroler yang berkolaborasi dengan teknologi internet, 
yang saat ini dikenal dengan Internet of Things (IoT).

Contoh peranan mikrokontroler dalam perkembangan IoT yang dapat dilihat saat ini dan sering ditemui yaitu teknologi wearable. Teknologi wearable merupakan teknologi di mana aksesoris yang dipakai, memiliki manfaat dan terkoneksi dengan internet. Sebagai contoh, teknologi wearable yang sering ditemukan adalah smartwatch, yang biasanya ditemukan pada Android Wear, Apple Watch ataupun Pebble. Smartband seperti Xiaomi Mi Band dan FitBit memiliki manfaat yang sama, namun difokuskan kepada solusi di bidang kesehatan (fitness). Contoh lain, teknologi IoT sudah dapat diimplementasikan pada rumah yaitu Home Automation seperti Nest yang merupakan sistem IoT yang mencakup pendeteksian suhu (thermostat) dan sistem keamanan (security sistem).

Kemajuan teknologi IoT di berbagai bidang, menyebabkan industri elektronika telah mengembangkan berbagai perangkat keras (hardware) dan perangkat lunak (software) yang mendukung pemanfaatan IoT secara luas. Sistem pengendalian jarak jauh (remote control system) menjadi lingkup studi/riset yang terus menerus dikembangkan seiring dengan pemanfaatan teknologi IoT di masyarakat dan industri. Kalangan pendidikan baik pada jenjang menengah (SMK) dan jenjang pendidikan tinggi (PTN) juga mulai banyak mengajarkan pemanfaatan aplikasi IoT sebagai salah satu mata ajar penting untuk diajarkan kepada para siswa/mahasiswa.
Pengetahuan dan keterampilan teknis untuk memanfaatkan teknologi IoT juga diperlukan untuk diberikan kepada para guru SMK untuk nantinya bisa mengajarkannya kepada para siswa.

SMK kedepannya akan menjadi salah satu penghasil tenaga kerja produktif dengan kompetensi pada bidang keahlian tertentu. Lulusan SMK, terlebih lagi untuk SMK program keahlian elektronika industri diharapkan mampu mengikuti perkembangan teknologi yang berubah demikian cepat, karena penetrasi teknologi informasi yang demikian hebat. Peluang untuk mengisi lowongan pekerjaan pada sektor industri semakin terbuka dengan hadirnya teknologi internet yang pengaplikasiannya berbasis IoT. Teknologi IoT dengan berbagai penerapannya menjadi tantangan bagi SMK, khususnya program keahlian elektronika industri untuk lebih dalam mempelajari dan mempraktikannya. Dengan peluang tersebut, maka SMK perlu membekali lulusannya dengan aplikasi teknologi baru. Upaya itu bisa dilakukan dengan mendorong para guru di SMK untuk terus meningkatkan kompetensi profesionalnya dengan pengetahuan dan keterampilan teknik.

\section{METODE PELAKSANAAN}

Pelaksanaan kegiatan workshop ini dilakukan secara daring menggunakan aplikasi zoom meeting, karena masih berada dalam masa pandemi Covid-19 (Pemberlakuan Pembatasan Kegiatan Masyarakat/ PPKM). Walaupun dilakukan secara daring, sebagian peserta telah 
menyiapkan peralatan praktik berupa ESP32 IoT board sehingga dapat melakukan praktik secara luring di sekolah. Dalam workshop ini diberikan 4 (empat) modul materi, yakni : perkembangan teknologi IoT, pengenalan perangkat keras ESP32 IoT development board, pengenalan platform aplikasi IoT dan praktikum sederhana IoT menggunakan ESP32.

\section{HASIL DAN PEMBAHASAN}

Kegiatan workshop pemanfaatan teknologi Internet of Things (IoT) menggunakan mikrokontroler ESP32 telah dilaksanakan secara daring (zoom meeting) dan beberapa peserta mengikutinya secara luring di sekolah. Kegiatan dimulai dengan menanyakan asal SMK dan program keahlian dari masing-masing peserta. Dari 20 (duapuluh) peserta yang hadir, berasal dari beberapa SMK di wilayah Jakarta, Bekasi, Depok, Bogor dan Cibinong. Adapun program keahlian/kompetensi keahlian dari para peserta adalah elektronika industri, mekatronika, komputer jaringan, dan audio video. Gambar 1 menunjukkan kegiatan pembukaan workshop pemanfaatan teknologi IoT untuk para guru SMK.

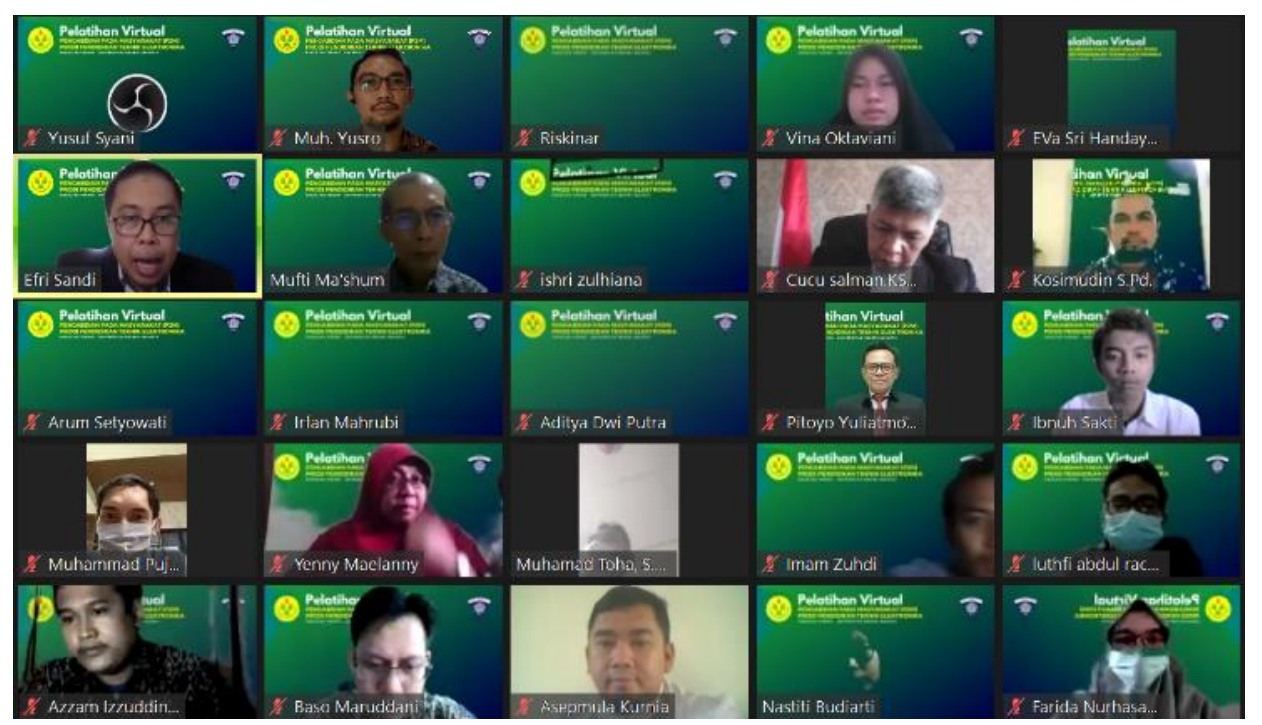

Gambar 1. Pembukaan Kegiatan Pengabdian Kepada Masyarakat

Dalam workshop, peserta diberikan materi tentang pemanfaatan teknologi IoT baik materi teori maupun praktik, seperti ditunjukkan pada Tabel 1. Untuk materi praktik, peserta diminta untuk meng-install software Arduino IDE pada perangkat komputernya baik PC maupun laptop, menyiapkan hardware ESP32 IoT serta kabel USB untuk koneksi antara ESP32 dengan komputer yang digunakan saat memprogram. Gambar 2 memperlihatkan suasana pelatihan saat salah satu materi workshop disampaikan kepada peserta. 
Tabel 1. Materi Workshop dan Narasuber

\begin{tabular}{llll}
\hline No & Materi & Narasumber & Durasi \\
\hline 1 & $\begin{array}{l}\text { Perkembangan dan Pemanfaatan } \\
\text { Teknologi IoT }\end{array}$ & $\begin{array}{l}\text { Muhammad Yusro } \\
\text { \& Aodah Diamah }\end{array}$ & 2 JP \\
\hline 2 & Pengenalan ESP32 IoT Board & Azzam Izzudin & 1 JP \\
\hline 3 & Platform Aplikasi IoT & Ibnuh Sakti & 1 JP \\
\hline 4 & Praktikum 1-2 menggunakan ESP32 & $\begin{array}{l}\text { Imam Zuhdi \& } \\
\text { Ibnuh Sakti }\end{array}$ & 2 JP \\
& IoT Board & Imam Zuhdi \& & 2 JP \\
\hline 5 & Praktikum 3-4 menggunakan ESP32 & Azzam Izzudin & \\
& IoT Board & & 2 JP \\
\hline 6 & Tugas Mandiri & Total Jam & $\mathbf{1 0 ~ J P}$ \\
\hline & & & \\
\hline
\end{tabular}

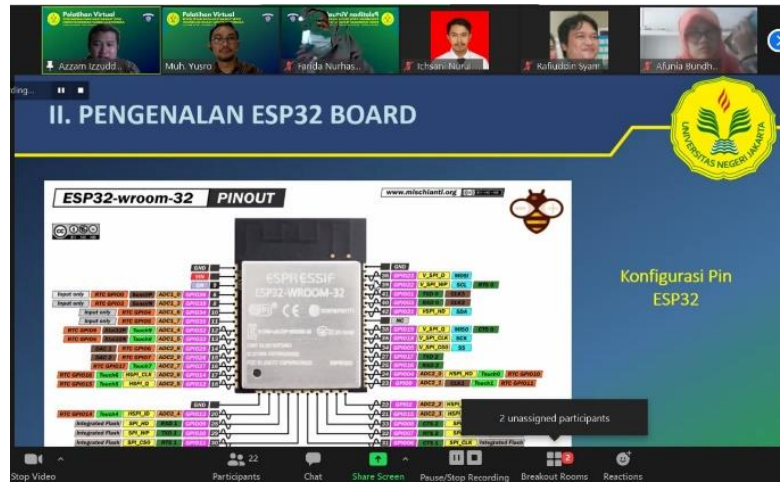

Gambar 2. Pemberian Materi pada Workshop Pemanfaatan IoT

Pada sessi ke-1 workshop, peserta diberikan materi tentang pengertian IoT, perkembangan mikrokontroler untuk IoT, perangkat teknologi IoT dan aplikasi IoT di berbagai bidang. Workshop sessi ke-2 diberikan materi tentang pengenalan perangkat ESP32, yakni spesifikasi dan keunggulan ESP32, konfigurasi ESP32 dan instalasi ESP32. Workshop sessi ke-3 diberikan materi tentang platform aplikasi IoT yang banyak digunakan masyarakat, yakni aplikasi blynk, thingspeak dan ubidots. Sessi ke-3 ini cukup menantang peserta, dikarenakan aplikasi ini menampilkan fitur yang menarik ditampilkan pada aplikasi mobile (OS Android). Khusus pada sessi ke-4 para peserta diberikan materi praktikum menggunakan hardware ESP32 dan menggunakan aplikasi IoT. Pada sessi ini, peserta mengikuti kegiatan secara daring dan luring dengan melakukan praktik langsung menggunakan perangkat ESP32. Gambar 3 menunjukkan kegiatan praktikum IoT ESP32 yang dilakukan secara luring oleh guru SMKN 1 Cibinong dengan melibatkan beberapa siswa pilihan. 


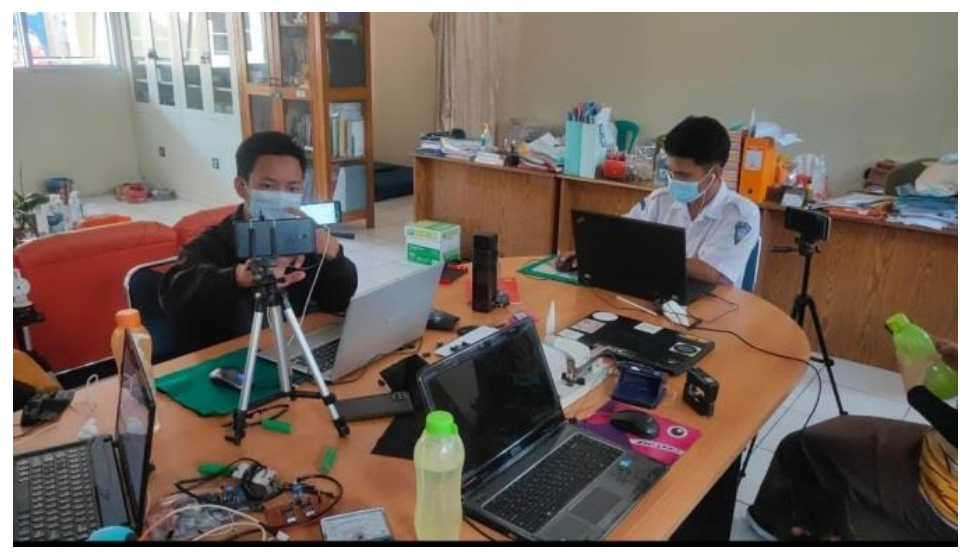

Gambar 3. Praktik IoT ESP32 yang Dilakukan Luring di SMKN 1 Cibinong

Materi praktikum ini memberikan keterampilan teknis kepada peserta tentang teknik mengakses GPIO pada ESP32, membuat percobaan blinking LED pada ESP32, menggunakan serial monitor pada Arduino IDE dan menghubungkan ESP32 ke jaringan internet. Gambar 4 menunjukkan tampilan praktik memilih board dan port pada bagian tools arduino IDE.

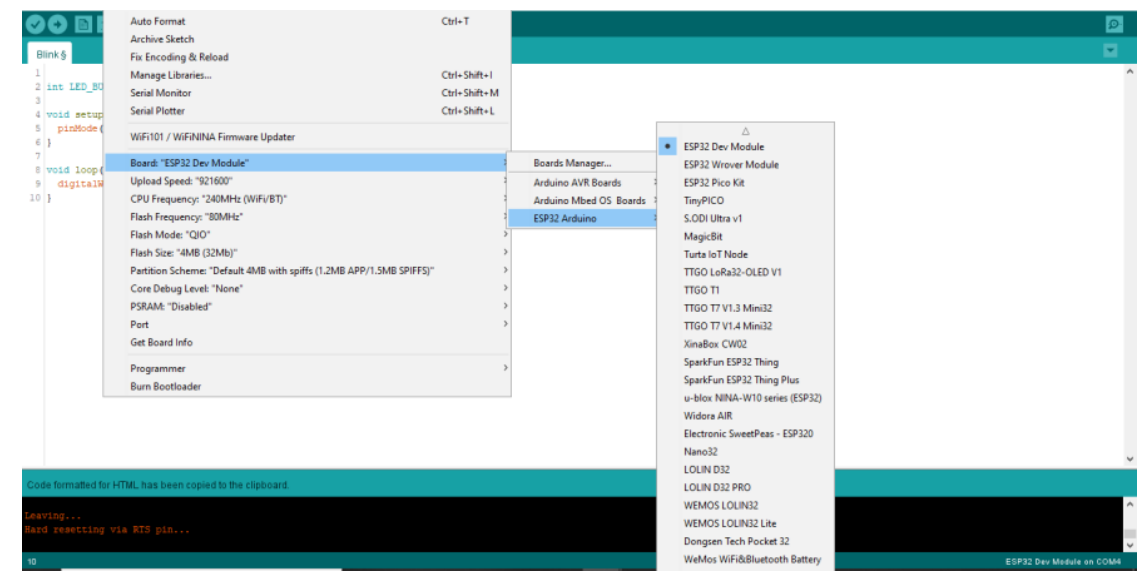

Gambar 4. Praktik Memilih Board dan Port pada Tools Arduino IDE

Pada sessi ke-4 para peserta juga diajarkan teknik mengkonfigurasi ESP32 board dengan beberapa perangkat input/output, misalnya ESP32 yang dihubungkan dengan sensor. Gambar 5 memperlihatkan salah satu bentuk konfigurasi rangkaian ESP32 yang dihubungkan dengan input sensor dan output relay. 


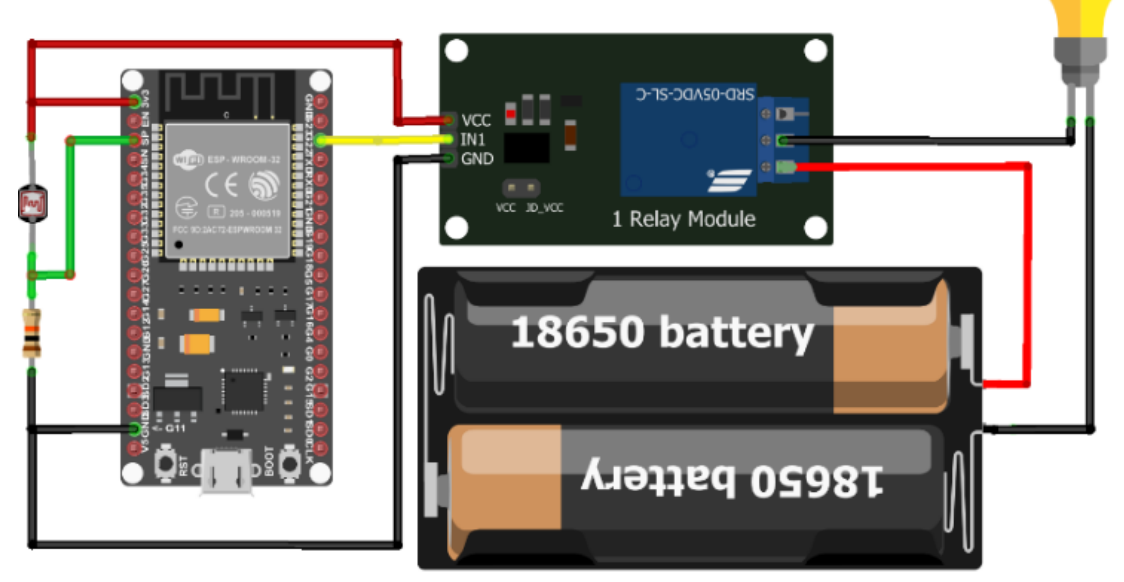

fritzing

Gambar 5. Praktik Mengontrol Relay dengan Sensor LDR pada ESP32

Dari diskusi narasumber dan peserta diperoleh informasi bahwasanya kegiatan workshop ini sangat bermanfaat untuk para guru SMK dalam menambah informasi, pengetahuan dan ketrampilan memanfaatkan teknologi IoT. Materi aplikasi IoT sangat menarik karena sangat relevan dan diperlukan oleh para guru dalam meningkatkan kompetensi keilmuan bidang elektronika industri, terlebih kemajuan teknologi internet saat ini yang memunculkan banyak aplikasi sistem pengendalian jarak jauh (remote control system). Sebagai kelanjutan dari workshop ini adalah para guru akan terus mengasah keterampilan tekniknya secara mandiri dan berkelompok di SMK masing-masing dengan menggunakan $e$ modul IoT yang dibagikan saat pelatihan. Keterbatasan waktu workshop menjadikan tidak semua materi dapat dipelajari, selain itu pembelajaran virtual melalui zoom juga membatasi lingkup kegiatan praktikum aplikasi IoT menggunakan ESP32.

\section{PENUTUP}

Workshop pemanfaatan teknologi Internet of Things (IoT) menggunakan mikrokontroler telah dilaksanakan secara virtual melalui zoom meeting yang diikuti oleh 20 (duapuluh) peserta guru SMK di wilayah Jakarta, Bekasi, Cibinong, dan Bogor. Peserta mendapatkan materi teori dan praktik terkait teknologi IoT menggunakan mikrokontroler ESP32 IoT development board dan pemanfaatan aplikasi IoT blynk, thinkspeak dan ubidots. Peserta yang berasal dari beberapa program keahlian ini mendapatkan banyak informasi dan pengetahuan baru tentang IoT dan aplikasinya yang akan diajarkan kepada para siswa di SMK nya. Peserta memberikan usulan agar workshop selanjutnya dapat dilaksanakan secara luring dan waktu pembelajarannya lebih lama, sehingga dapat mempraktikan seluruh contoh aplikasi IoT yang ada pada modul workshop. 


\section{DAFTAR PUSTAKA}

ASIOTI. (2020). Tiga sektor IoT ini tumbuh pesat selama pandemi. https://www.asioti.org/pressrelease/

Bansal, M., \& Gandhi, B. (2018). IoT Based Development Boards for Smart Healthcare Applications. 2018 4th International Conference on Computing Communication and Automation (ICCCA), 1-7. https://doi.org/10.1109/CCAA.20 18.8777572

Chieochan, O., Saokaew, A., \& Boonchieng, E. (2017). An integrated system of applying the use of Internet of Things, RFID and cloud computing: A case study of logistic management of Electricity Generation Authority of Thailand (EGAT) Mae Mao Lignite Coal Mining, Lampang, Thailand. 2017 9th International Conference on Knowledge and Smart Technology: Crunching Information of Everything, KST 2017, 156-161. https://doi.org/10.1109/KST.2017. 7886126

Firdaus, R., \& Mulyana, E. (2018). Smart Building Lighting System. IOP Conference Series: Materials Science and Engineering, 384(1). https://doi.org/10.1088/1757899X/384/1/012071

Gunther Gridling, B. W. (2007). Introduction to Microcontrollers. JSC. (2017). Pemanfaatan Teknologi Internet of Things (IoT) di Jakarta Smart City. https://smartcity.jakarta.go.id/blog /177/pemanfaatan-teknologiinternet-of-things-iot-di-jakartasmart-city

Kemendikbud. (2020). Menyelaraskan Perkembangan Industri 4.0 dengan IoT. https://www.vokasi.kemdikbud.go .id/read/menyelaraskanperkembangan-industri-4-0dengan-iot

Mishra, D., Khan, A., Tiwari, R., \& Upadhay, S. (2018). Automated Irrigation System-IoT Based Approach. Proceedings - 2018 3rd International Conference On Internet of Things: Smart Innovation and Usages, IoT-SIU 2018, 3-6. https://doi.org/10.1109/IoTSIU.2018.8519886

Nasir, H., Aziz, W. B. W., Ali, F., Kadir, K., \& Khan, S. (2018). The Implementation of IoT Based Smart Refrigerator System. 2018 2nd International Conference on Smart Sensors and Application, ICSSA 2018, 48-52. https://doi.org/10.1109/ICSSA.20 18.8535867

Nguyen, T. D., Tran, V. K., Nguyen, T. D., Le, N. T., \& Le, M. H. (2018). IoT-Based Smart Plug-In Device for Home Energy Management System. Proceedings 2018 4th International Conference on Green Technology and Sustainable Development, GTSD 2018, 734-738. https://doi.org/10.1109/GTSD.201 8.8595615 
Saber, H. M., \& Al-Salihi, N. K. (2017). IoT: Secured and automated house. Proceedings International Carnahan Conference on Security Technology, 2017-Octob, 1-6. https://doi.org/10.1109/CCST.201 7.8167862

Sakti, I., Yusro, M., \& Diamah, A. (2021). A Quadcopter for Monitoring System of Carbon Monoxide Levels Based on Internet of Things. International Conference on Intelligent Technologies (CONIT), 1-5.

Shri Pradha, R., Suryaswetha, V. P., Senthil, K. M., Ajayan, J., Jayageetha, J., \& Karhikeyan, A. (2019). Agricultural Field Monitoring using IoT. 2019 5th International Conference on Advanced Computing and Communication Systems, ICACCS
2019, 277-280.

https://doi.org/10.1109/ICACCS.2 019.8728508

Sushanth, G., \& Sujatha, S. (2018). IOT Based Smart Agriculture System. 2018 International Conference on Wireless Communications, Signal Processing and Networking, WiSPNET 2018, 0-3. https://doi.org/10.1109/WiSPNET .2018 .8538702

Telkomsel. (2020). Internet of Things: Definisi, Sejarah, Manfaat \& Penerapan. https://telkomseliot.com/id/beritainsight/internet-of-things-definisisejarah-manfaat-penerapan

Wantiknas. (2020). IoT di Indonesia dan Peta Jalan ke Depan. http://www.wantiknas.go.id/id/ber ita/iot-di-indonesia-dan-petajalan-ke-depan 